\title{
8
}

\section{im

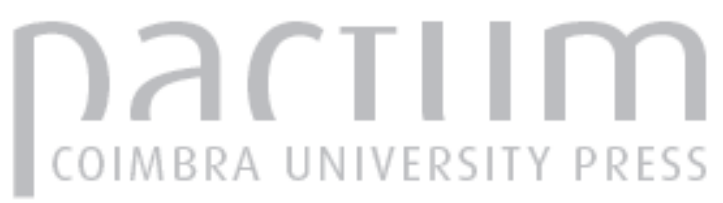

À beira do respeito: investigações ontológicas e fenomenológicas sobre a ética das plantas

\author{
Autor(es): $\quad$ Marder, Michael
}

Publicado por: Imprensa da Universidade de Coimbra

URL persistente:

URI:http://hdl.handle.net/10316.2/42850

DOI:

DOI:http://dx.doi.org/10.14195/0872-0851_50_5

Accessed : $\quad$ 26-Apr-2023 14:31:58

A navegação consulta e descarregamento dos títulos inseridos nas Bibliotecas Digitais UC Digitalis, UC Pombalina e UC Impactum, pressupõem a aceitação plena e sem reservas dos Termos e Condições de Uso destas Bibliotecas Digitais, disponíveis em https://digitalis.uc.pt/pt-pt/termos.

Conforme exposto nos referidos Termos e Condições de Uso, o descarregamento de títulos de acesso restrito requer uma licença válida de autorização devendo o utilizador aceder ao(s) documento(s) a partir de um endereço de IP da instituição detentora da supramencionada licença.

Ao utilizador é apenas permitido o descarregamento para uso pessoal, pelo que o emprego do(s) título(s) descarregado(s) para outro fim, designadamente comercial, carece de autorização do respetivo autor ou editor da obra.

Na medida em que todas as obras da UC Digitalis se encontram protegidas pelo Código do Direito de Autor e Direitos Conexos e demais legislação aplicável, toda a cópia, parcial ou total, deste documento, nos casos em que é legalmente admitida, deverá conter ou fazer-se acompanhar por este aviso.

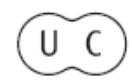




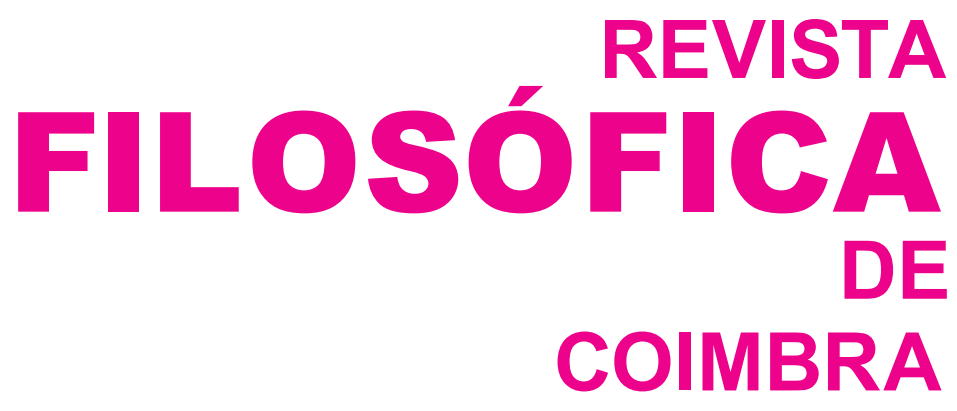

vol. 25 - número 50 - outubro 2016

vol. 25 - número 50 - outubro 2016

Fundação Eng. António de Almeida

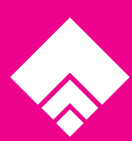




\title{
À BEIRA DO RESPEITO: INVESTIGAÇÕES ONTOLÓGICAS E FENOMENOLÓGICAS SOBRE A ÉTICA DAS PLANTAS
}

THE EDGE OF RESPECT: ONTOLOGICAL AND PHENOMENOLOGICAL INVESTIGATIONS

ON THE ETHICS OF PLANTS

\section{MICHAEL MARDER}

Resumo: Em contraste com os paradigmas legais, metafisicamente carregados, e epistemológicos, a interpretação ontológica do respeito concerne não apenas à relação entre o "sujeito" e o "objeto" (ou, melhor, entre o providenciador e o receptor desta atitude), mas também ao ser daquele que é respeitado e daquele que respeita. Este artigo desenvolve uma ontologia do respeito com vista ao tratamento humanos das plantas e esmiúça os sentidos da vida vegetal que germinam nesta relação. Aquilo que está em causa, afirmo, não é tanto uma ontologia objetiva quanto uma abertura fenomenológica dos sentidos das vidas humana e vegetal, analisadas "a partir de dentro", isto é, tanto no contexto das interações entre elas quanto a partir do ponto de vista único próprio de cada tipo de ente. Longe de ser um suplemento ético a uma descrição teórica dos entes vegetais, o respeito é o prisma através do qual podemos primeiro conquistar o acesso a uma ontologia da planta.

Palavras-chave: Repeito, Vida Vegetal, Sujeito, Distância, veneratio vitae.

\begin{abstract}
In contrast to the legal, metaphysically laden, and epistemological paradigms, the ontological interpretation of respect concerns not only the relation between the "subject" and the "object" (or, better, the provider and the recipient, of this attitude) but also

Резюме: отличие от метафизи-
ческих и эпистемологических
парадигм уважения, феноменолого-
-онтологическая интерпретация
данного понятия относится не
только к связи между “субъектом”
и “объектом” (другими словами,

* IKERBASQUE / Universidade do País Basco (UPV-EHU), Vitoria-Gasteiz Associate Professor, Institute of the Humanisties (University of Diego Portales, Chile); email: michael.marder@gmail.com
\end{abstract}


the being of the respected and the respecting. This paper develops an ontology of respect with regard to the human treatment of plants and teases out the meanings of vegetal life that germinate in this relation. What is at stake, I claim, is not so much an objective ontology as the phenomenological disclosure of the meanings of human and vegetal lives, construed "from within," i.e., both in the context of the interactions between them and from the unique standpoint proper to each kind of being. Far from an ethical supplement to a theoretical description of vegetal beings, respect is the prism through which we may first gain access to plant ontology.

Key Words: Respect, Vegetal Life, Subject, Distance, veneratio vitae.

донору и получателю), а к бытию уважающего и уважаемого. В данной работе, я развиваю онтологию уважения на примере человеческого подхода к растительному миру и рассматриваю значения вегетативной жизни, зараждающиеся в этом подходе. Подчёркиваю, что особенна важна не столько объективная онтология, сколько феноменологическое раскрытие того, что означают существования растения и человека, которые можно уловить лишь “изнутри", т.е. в контексте их интеракций и с точки зрения каждого вида бытия. Вместо этического приложения к теории вегетативной жизни, уважение представляет собой призму, через которую мы можем получить доступ к онтологии растений.

$\begin{array}{cr}\text { Ключевые слова: } & \text { уважение, } \\ \text { растительный } & \text { мир, } \\ \text { расстояние, veneratio vitae. }\end{array}$

Nun, nun müssen dafür Worte, wie Blumen, entstehen Hölderlin, "Brot und Wein"1

Aqueles que desejam levar a cabo uma abordagem que respeite as plantas não devem ficar satisfeitos com fazer prescrições moralizantes ou generalizações normativas abrangentes sobre a respeitabilidade da vida como tal e como um todo. Se a ética das plantas e, por extensão, o respeito por aquilo a que os gregos chamavam phutoi, "seres que crescem", é suposta adquirir todo o peso de um imperativo, esta deve estar enraizada na questão ontológica sobre a existência desses seres que crescem. "Qual é o sentido do respeito pela vida vegetal?" é a forma ontológica da questão que problematiza o fenó-

\footnotetext{
1 "Agora, agora têm de surgir para isso palavras, como flores". Hölderlin, "Pão e Vinho".
} 
meno do respeito, tanto quanto a natureza dos seus potenciais beneficiários. Levantá-la é já encontrar-se à beira do respeito, no ponto ou no limiar onde a tentativa de consolidar a ética das plantas assume a sua própria obrigação de proceder de forma ética e responsável, na medida em que meticulosamente fundamenta as suas conclusões provisórias e recomendações numa interpretação cuidadosa de ontologias das plantas, tão múltiplas, anárquicas e dispersas quanto o são os próprios seres vegetais.

A ênfase ontológica é precisamente o ponto onde os atuais ensaios divergem de outras atuais perspectivas sobre a ética das plantas. Frequentemente, quando o assunto é o tratamento ético das plantas, o paradigma predominante é o de um pluralismo ou legalismo puramente formal, em dívida com o discurso essencialmente moderno dos direitos. Embora revolucionário nas suas afirmações, o agora clássico Should Trees Have Standing? de Christopher Stone (1972) enquadra-se nessa tradição, na medida em que defende a visão de que os "objetos naturais" devem ser protegidos como valiosos em si mesmos $^{2}$. A inclusão das plantas sob a categoria de objetos intrinsecamente valiosos atesta a ambivalência da ênfase humanista sobre os direitos que ultrapassaram os seus limites estendendo-se a seres não-humanos. Sendo um puro absurdo legalista, o discurso sobre os "direitos dos objetos" mina o próprio pensamento ético que se destina a reforçar.

Recentemente, Matthew Hall (2011) tem-se esforçado por justificar a ética das plantas no que chama personalidade das plantas, dando mais atenção à ontologia vegetal ${ }^{3}$. A imagem conceptual geral e já idealizada das plantas que emerge desta monografia é, no entanto, desviada na direção dos valores metafísicos (autonomia, capacidade ativa de ação, etc.) que foram atribuídos às pessoas humanas na história do pensamento ocidental. É dado como certo que o destinatário legítimo de uma atitude de respeito é um agente autónomo e, com base nesta suposição não examinada, que a descoberta destas mesmas características em plantas justificará a injunção para respeitá-las também. De modo muito semelhante ao discurso dos direitos morais que inclui "objetos naturais" sob o título jurídico já existente, a atribuição de (uma igualmente formal) personalidade às plantas, e o convite para tratá-las como se trata uma pessoa, assimila a ontologia vegetal a categorias filosóficas modernas bem estabelecidas, muitas delas idealizações fictícias da condição humana. Tudo o que é único sobre o ser das plantas e sobre a relação humana com elas está irremediavelmente perdido em ambas as operações conceptuais.

$\mathrm{O}$ argumento epistemológico para a respeitabilidade para com as plan-

2 Christopher D. Stone, Should Trees Have Standing? Law, Morality, and the Environment, Third Edition (Oxford: Oxford University Press, 2010[1972]).

3 Matthew Hall, Plants as Persons: A Philosophical Botany (Albany, NY: SUNY, 2011). 
tas encontra a sua mais clara formulação em Speaking to Trees $(1992)^{4}$, de Erazim Kohák. De acordo com Kohák, uma mudança no comportamento humano, levando-nos a falar com - e não apenas sobre - as plantas pode vir a reforçar um comportamento de respeito para com elas. Se é verdade que, na abordagem de um ser, reconhecemos o seu status como separado de nós e não totalmente sob nosso controle, a mudança epistemológica é, em última análise, demasiado antropocêntrica para atingir o seu objetivo declarado. Mais uma vez, ela corre o risco de inscrever os seres vegetais dentro da comunidade humana, linguisticamente mediada, como seus membros deficientes, incapazes de responder em espécie. O privilégio de expressão verbal, totalmente ausente entre as formas possíveis nas quais as plantas se relacionam com o mundo em que crescem, falha em prestar a devida atenção para a especificidade do seu modo de vida. E, ao não fazê-lo, desrespeita o próprio ser das plantas 5 .

Em contraste com os metafisicamente sobrecarregados paradigmas legais e epistemológicos que abordei acima, a interpretação ontológica do respeito, avançada por Martin Heidegger na sua leitura da ética kantiana, concerne não apenas a relação entre o "sujeito" e o "objeto" desta atitude, ou melhor, entre quem o atribui e quem o recebe, mas também o ser do respeitado e o respeitar. A maior parte do meu argumento vai, então, lidar com a ontologia do respeito, salientando a sua importância para o tratamento humano das plantas, bem como para os significados da vida vegetal que germinam nessa

4 Erazim Kohák, “Speaking to Trees,” Critical Review 6 (1992), 371-388.

5 Temos também de mencionar que a ontologia das plantas pode ser reconsiderada, no seguimento dos dados derivados dos campos florescentes dos estudos sobre neurobiologia das plantas e inteligência das plantas, inaugurados, entre outros, por Richard Karban e Anthony Trewavas. As investigações ontológicas sobre ética das plantas não são uma resposta às tentativas de extrair consequências éticas diretamente da investigação empírica levada a cabo nestes campos, mas um quadro filosófico dentro do qual tais dados podem ser interpretados. As contribuições de Karban e de Trewavas para a compreensão do comportamento das plantas são demasiado numerosas para serem resumidas neste artigo; no entanto, vale a pena mencionar as publicações mais importantes dos dois cientistas. No caso de Karban, elas incluem (com K. Shioriji), "Self-Recognition Affects Plant Communication and Defense." Ecology Letters 12 (2009), 502-506; "Plant Behavior and Communication" Ecology Letters 11 (2008), 727-739; (com Ian T. Baldwin), (com M. Huntzinger), How To Do Ecology: A Concise Handbook (Princeton, NJ: Princeton University Press, 2006); Induced Responses to Herbivory (Chicago: The University of Chicago Press, 1997). O inovador trabalho de Trewavas inclui "Green Plants as Intelligent Organisms," Trends in Plant Science 10 (2005), 413-419; "Aspects of Plant Intelligence: An Answer to Firn," Annals of Botany, 93 (2004), 353-357; "Aspects of plant intelligence," Annals of Botany 92 (2003), 1-20; "How Plants Learn," Proceedings of the National Academy of Sciences of the United States of America 96 (1999), 4216-8. 
relação. O que está em jogo aqui, afirmo, não é tanto uma ontologia objetiva, mas sim a desobstrução fenomenológica dos significados da vida humana e vegetal interpretadas "de dentro", ou seja, tanto no contexto das interações entre elas e partindo do ponto de vista único próprio de cada tipo de ser. Longe de um suplemento de ética para a descrição ontológica dos seres vegetais, o respeito é o prisma através do qual poderemos primeiro ter acesso à ontologia da planta. Concluo com a consideração do ser planta, visto numa abordagem que respeite a vida vegetal, como o fundamento de uma ética prática das plantas.

\section{A distância do Respeito.}

Ao fazer uma démarche ontológica longe do individualismo formalista do pensamento moderno que se inclina para o discurso dos direitos e da personalidade, encontramo-nos à beira do respeito: no limiar de um novo começo que remonta à origem grega da filosofia e, ao mesmo momento, às margens mais externas da ética, sensível ao ser das próprias plantas. Nada, porém, garante que nós alguma vez atravessemos, de uma vez por todas, esse limiar e, ao atravessá-lo, entremos na terra prometida conhecida como o "reino dos fins", onde as nossas relações com - ou, inversamente, o nosso desligamento das - plantas seriam declaradas perfeitamente justas e equitativas com base numa máxima engenhosa, universalmente aplicável a todo e qualquer ser vegetal. Isso é porque estar à beira, a uma certa distância do ser que merece respeito é a condição da ética enquanto tal ${ }^{6}$. Respeito, ao contrário de empatia, inevitavelmente implica, aponta na direção de e, ao mesmo tempo, salvaguarda uma distância mínima entre o que respeita e o que é respeitado, do mesmo modo que a visão envolve o "terceiro elemento" de luz e um espaço de separação para além da díade do ver e do visto. Mesmo em matéria de autorrespeito essa distância permanece indelével, uma vez que, quando eu estender a relação a mim mesmo, eu sou, assim, separado de mim mesmo como objeto de comportamento de respeito.

$\mathrm{O}$ hiato entre respeitar e respeitado implica incalculavelmente mais do que o físico, o ôntico, a distância empiricamente mensurável entre os dois,

6 John Sallis atribui o mesmo predicado de estar à beira ou à margem à filosofia como um todo, a qual, para permanecer verdadeira em relação à sua vocação, tem de se confinar a ela mesma a uma série de novos começos: "Toda a determinação originária está situada à margem... Porque a filosofia seria tal orientação o mais radical [para a origem], ela tem de se submeter, no mais elevado grau, à margem; ela tem de assentir estar ela mesma determinada enquanto tal à margem." [The Verge of Philosophy (Chicago: University of Chicago Press, 2008), 3] 
pois isso tem a ver, sobretudo, com a separação ontológica dentro do ser e entre regiões do ser - por exemplo, o vegetal e o humano. Obviamente, a ontologia das plantas é distinta da dos seres humanos, desde que ela se foque nos modos nutricionais nas relações drasticamente diferentes destes seres com o meio ambiente, nas estratégias de adaptação, nas possibilidades de mobilidade, e assim por diante. Tanto é assim que, em relação às características empiricamente discerníveis e objetivamente descritíveis que consolidam sistemas tipológicos, classificatórios ou taxonómicos, as plantas parecem ser totalmente outras em relação aos os seres humanos e, no que diz respeito aos seres vivos, estão situadas na maior distância em relação a eles. E, no entanto, o quase consenso - na maioria das vezes, um acordo silencioso, vendo que a diferença entre os dois é demasiado evidente para ser explicitamente observada - sobre o tema da alteridade vegetal falhou no cultivo de uma atitude de respeito para com a vida da planta. Será esta falha atribuível, pelo menos em parte, a um esquecimento da ontologia da planta, que não coincide com o conjunto de características empíricas das plantas?

Ao longo da tradição da metafísica ocidental, a abordagem ontológica das plantas, que se estendeu de Aristóteles a Friedrich Nietzsche, visa a fundação subjacente da vida vegetal. Nos dois extremos da história da metafísica, Aristóteles chamou a esta fundação to threptikon, ou a alma vegetal, com as suas características capacidades de alimentação e procriação, enquanto Nietzsche identificou-a com a vontade de poder, expressa na positividade do crescimento, do excesso e da expansão, onde nada falta ${ }^{7}$. É de notar que incursões metafísicas no domínio da ontologia das plantas chegaram a uma conclusão diametralmente oposta às enumerações impressionistas e taxonómicas das diferenças entre seres vegetais e humanos: destacaram o stratum comum da vida (o mais prevalecente e banal, do ponto de vista da metafísica). De modo semelhante às plantas, os humanos participam das atividades nutritivas e reprodutivas do threptikon, embora, de acordo com Aristóteles, também possuam uma alma sensitiva que compartilham com os animais e uma alma cognitiva que define propriamente a sua humanidade. De novo tal como as plantas, animais e humanos são phutoi, "seres que crescem", mesmo que, para além do crescimento do cabelo, unhas, garras, pele ou penas, correspondentes à proliferação vegetal de seus corpos, eles apresentem outros tipos de crescimento, tal como o crescimento da experiência ou intelectual. (Daí a referência de Platão aos humanos como "plantas celestes", presos por raízes invisíveis ao mundo das $\operatorname{Ideias}^{8}$ ). Um tratamento ôntico-empírico dos seres fornece-nos catálogos de diferenças superficiais; especulações ontológico-metafísicas sobre o ser enquanto tal desvelam uma fundação pro-

7 Cf. Aristóteles, De Anima, 413b, 1-10; Friedrich Nietzsche, The Will to Power, translated by Walter Kaufman and R.J. Hollingdale (New York: Vintage Books, 1968), 349.

8 Platão, Timeu, 90a. 
funda na mesmidade. O que deve, então, ser respeitado na vida vegetal? A sua diferença em relação ao modus vivendi a que chamamos "humano" ou, pelo contrário, o facto de que ele é essencialmente o mesmo que a nossa vitalidade mais básica?

Os filósofos metafísicos equipararam a ontologia única das plantas a uma parte da existência humana limitada, grosseiramente material, não consciente e deplorável. Concedendo isso, seria um erro identificar a noção kantiana de subjetividade empírica, que consiste em necessidades materiais e preferências individuais, com a alma vegetal aristotélica. Mas, tendo dito isso, o paralelo entre os dois é esclarecedor. Para Immanuel Kant, a subjetividade empírica é o que menos merece respeito nos seres humanos, que são respeitáveis apenas como (reais ou potenciais) auto-legisladores e sujeitos autónomos da razão. Esta notável ausência de auto-respeito, quando se trata da dimensão material de nossas vidas, é sintomática de uma difamação do outro vegetal em nós; na verdade, é indicativo do apagamento da distância na subjetividade empírica em detrimento da hiper-inflada separação entre a subjetividade e o seu correlato transcendental. Noutras palavras, assim que cairmos nas armadilhas da metafísica, já não nos encontramos à beira da ontologia das plantas. Em vez disso, atravessamos o limiar e proclamamos que nós também somos plantas, embora plantas que são melhores, "celestiais", dotadas com as características transcendentais que nos diferenciam das "terrenas". Um sistema distinto de valorações é a priori construído para esta auto-definição, medindo a alma vegetal, bem como as suas subsequentes instanciações filosóficas, contra o padrão-ouro da razão antropocêntrica, que, invariavelmente, identifica esta alma com figuras de deficiência e falta. O domínio externo sobre e destruição da flora na escala global é o reflexo prático exterior desta avaliação tendenciosa e do desrespeito máximo em relação à dimensão puramente vegetal da nossa existência.

Além de fazer passar julgamentos metafísicos prefixados sobre o valor da vida vegetal, há outras maneiras de perder o estar-se à beira, no ponto onde ainda é possível respeitar o ser das plantas, pois nada é mais precário do que a distância constitutiva desta atitude que, embora incomensurável, exige ser calibrada com precisão. Esquematicamente, pode-se dizer que o respeito é um meio-termo, ladeado pelo amor, por um lado, e pela sacralização, por outro, não tão íntimo quanto o primeiro e não tão afastado como o último. Além disso, os contornos deste respeito ontológico ainda são visíveis na ética kantiana. Em A Metafísica dos Costumes, o filósofo alemão traça um contraste nítido entre o amor, que ele interpreta como o poder de atração, e o respeito, em que ele vê a força de repulsão. "O princípio do amor mútuo", escreve Kant, "adverte-os [aos seres humanos] para aproximarem-se uns dos outros; o do respeito que eles devem uns aos outros, para se manterem a uma 
distância uns dos outros..." . Ainda assim, a força de repulsão respeitosa deve ser moderada, de modo a não exagerar a distância do respeitado, sacralizado e completamente separado daquele que respeita. (O austero Deus monoteísta, devemos lembrar, não é respeitado, mas reverenciado. O cristianismo, por sua vez, tenta diminuir a distância entre o humano e o divino, convertendo a força centrípeta de repulsão, que emana do sagrado, no poder centrífugo do amor.) $\mathrm{O}$ delicado equilíbrio de respeito exige apenas o grau certo de tensão entre o respeitar e o respeitado, da mesma forma que aquele que vê deve estar situado a uma distância ótima daquilo que é visto para discernir os contornos de seu objeto. É por isso que Emmanuel Levinas define famosamente a ética como uma ótica ${ }^{10}$, sendo que o respeito, o mais teórico de todos os comportamentos éticos, está intimamente ligado, nos planos etimológico e conceptual, ao espetáculo, à especulação e à especularidade.

Uma abordagem respeitosa para com as plantas tem que lidar com a difícil tarefa de esculpir um nicho entre o amor e reverência. Aqueles motivados pelo amor à natureza desejam, na maioria das vezes, diminuir a sensação de alienação, as distâncias subjetivas e (correspondentemente) objetivas que os separam do mundo natural. O obstáculo óbvio ao amor pelas plantas é que, pelo menos do ponto de vista antropocêntrico, é extremamente assimétrico, desprovido do princípio kantiano de mutualidade. A orquídea que eu rego e cuido não responde ao meu cuidado como faz um cão, mas isso não quer dizer que a planta é decididamente sem resposta. Mesmo se assumíssemos, concesso non dato, que o pressuposto antropocêntrico fosse correto, não deveria ter impedido uma abordagem ética das plantas. Muito pelo contrário, teria sido o melhor teste de conduta ética, não afetado pelas expectativas de retorno ou de benefícios futuros para o agente ético, sendo estes retornos tão simbólicos quanto o simples reconhecimento das suas ações. A incapacidade das plantas de reconhecer o meu comportamento como ético torna este comportamento... tanto mais ético.

A assimetria relacional é, de fato, uma das condições prévias para a ética no pensamento de Levinas e do seu antecessor, Martin Buber, o qual, em Eu $e T u$, contempla a possibilidade de experienciar uma forte ligação emocional a uma árvore particular. Rompendo com a ética antropocêntrica, Buber descreve uma situação em que a árvore deixa de ser um mero "isso", objetivamente conhecido pela ciência que o dissolve em componentes químicos, e, em vez disso, torna-se um $T u$, um parceiro de pleno direito numa relação

9 Immanuel Kant, The Metaphysics of Morals, edited by Mary Gregor (Cambridge: Cambridge University Press, 1996), 198.

10 Emmanuel Levinas, Totality and Infinity: An Essay on Exteriority, translated by Alphonso Lingis (Pittsburgh: Duquesne University Press, 1969), 23. 
(Beziehung $)^{11}$. No entanto, uma aproximação amorosa, não trianguladas por um terceiro, elimina a distância necessária para o respeito ${ }^{12}$. Os limites do amor retraçam as margens enevoadas do objeto que se torna imperceptível, logo que a distância entre o amante e o amado desaparece. Amar uma planta, ou sentir empatia com ela, é perdê-la de vista por completo e estar à beira de dissolver o ser de cada participante na relação diádica numa "síntese superior". Sem o suplemento de respeito, cultivando cuidadosamente a distância entre os dois, o amor é ontologicamente sufocante, na medida em que não permite que o amado seja mas antes lhe impinge o ser dele ou dela. $\mathrm{O}$ amor necessariamente exclui o terceiro (ou seja, todas as outras plantas, além dessa orquídea, desta árvore ou da rosa que tanto encantou o Principezinho de Saint-Exupéry) da díade hermeticamente fechada e é, portanto, fundamentalmente injusto. A diminuição drástica da distância entre o eu e uma singular árvore-tu vem à custa de aumentar o hiato entre este eu e todas as outras árvores, para não mencionar aquelas plantas, como os arbustos e as ervas daninhas, que, muito provavelmente, não vão provocar o mesmo sentimento como uma bétula velha que se conhece desde a infância ${ }^{13}$.

No outro extremo, os seres humanos experimentam a natureza como um objeto sagrado merecedor de reverência e adoração. Nas experiências religiosas, transcendentes, a distância em relação ao ser do reverenciado é magnificado ao ponto de um destacamento patente. Certamente, uma separação ontológica crescente pode fazer surgir o princípio da não interferência com a dinâmica inerente e os fins do mundo não humano, mas também se arrisca a repelir o objeto sacralizado e a torná-lo ontologicamente indiscernível. Os cultos de fertilidade mais antigos, que eram provavelmente as fontes mais profundas do sentimento religioso, coincidem, neste contexto, com algumas das tendências na filosofia recente, como a veneratio vitae, a reverência da vida, de Albert Schweitzer ${ }^{14}$. Não é por acaso que, de acordo com a tendên-

11 Buber, Martin. I and Thou, translated by Ronald Gregor Smith (London \& New York: Continuum, 2004), 15.

12 Sobre o criticismo de Levinas em relação a Buber, veja-se Robert Bernasconi, “'Failure of Communication' as a Surplus: Dialogue and Lack of Dialogue between Buber and Levinas," in The Provocation of Levinas: Rethinking the Other, edited by Robert Bernasconi \& David Wood (London \& New York: Routledge, 1988).

13 Nos protestos ambientais, o ato de se acorrentar a si mesmo a uma árvore - o ato que valeu aos ativistas ambientais o rótulo depreciativo de "tree huggers" - demonstra as limitações estratégicas de eliminar a distância (seja física, emocional ou ontológica) entre os participantes na relação humano-planta. É simplesmente impossível abraçar e, mais importante, poupar todas as árvores marcadas pelas madeireiras, desde que alguém catequize emocionalmente e se ligue fisicamente a uma árvore singular.

14 Albert Schweitzer, Reverence for Life: Sermons 1900-1919 (New York: Harper \& Row, 1969). 
cia geral de sacralização, a reverência é devida a uma categoria da vida abstrata, indiferenciada e mesmo totalizante, seguindo uma injunção que é tão indiscriminada e desatenta em relação ao ser do reverenciado que desemboca em desrespeito e provoca uma tensão ontológica entre as partes ao ponto de deixar andar. O problema com a sacralização da vida é que ela ignora o modo como se adequam um ao outro o sacralizar e o sacralizado, tanto quanto a apropriação (portanto, o ajuste) dessa relação em cada caso de envolvimento humano com um ser vivo. Na mesma linha, o respeito pela natureza de Paul Taylor ${ }^{15}$ reverte-se para o lado de reverência, tendo perdido de vista as ontologias singulares das plantas, animais e outros "seres naturais" que apelam à nossa sensibilidade moral. Parafraseando Kant, é portanto justo dizer que o amor sem respeito é cego, enquanto a reverência sem respeito é vazia.

Mesmo assim, qual é a distância ótima de respeito entre os excessos do amor e da reverência? Esta questão vai ao coração do funcionamento atual do respeito que, segundo a filosofia moral de Kant, depende de quão bem sucedido se é em moderar os dois sentimentos que acompanham a busca desatenta das nossas inclinações e desejos, ou seja, o amor-próprio, Eigenliebe, e a presunção, Eigendünkel ${ }^{16}$. Pondo de forma diferente, depende da acentuação das diferenças entre o sujeito empírico de necessidade e o sujeito transcendental, acentuação que conduz à formulação da lei moral. Mas se o amor-próprio é inversamente proporcional ao respeito, então a distância que se estende entre mim e o outro respeitado tem de ser imaginada verticalmente, em termos de minha auto-difamação ou humildade face a ele. Kant aponta para a verticalidade do respeito numa breve discussão de gratidão: "A gratidão não é, falando estritamente, amor em relação a um benfeitor da parte de alguém que ele pôs sob obrigação, mas respeito para com ele. Pois o amor universal do nosso próximo pode e tem de estar baseado na igualdade de deveres, enquanto na gratidão quem se põe sob obrigação está um nível mais abaixo do que o seu benfeitor"17. Supondo-se que o mesmo se aplica ao nosso respeito em relação às plantas, vislumbramos na obrigação, na gratidão e na humildade que posiciona o sujeito abaixo do "seu benfeitor" - aqui, uma planta - uma inversão ética da velha cadeia metafísica do ser, onde seres vegetais são invariavelmente classificados como menos que humanos. O desafio, no entanto, é interpretar o significado do nosso posicionamento "um degrau mais baixo" do que as plantas.

15 Paul W. Taylor, Respect for Nature: A Theory of Environmental Ethics (Princeton: Princeton University Press, 1986).

16 Immanuel Kant, Critique of Practical Reason, edited by Mary Gregor (Cambridge: Cambridge University Press, 1997), 63.

17 Kant, The Metaphysics of Morals, 206. 
A citação acima lida, da forma mais imediata, com o sentimento de gratidão que implica um respeito quase feudal oferecido como uma homenagem ao benfeitor, opondo-se ao amor igualitário do próximo, radicado em obrigações mútuas. Embora isso possa parecer contra-intuitivo, as criaturas não-humanas são nossas benfeitoras mais do que os outros seres humanos. É quase redundante perguntar: "Em que condições poderia o ser humano ser grato para as plantas?", vendo que as fontes da nossa gratidão são demasiado numerosas para serem listadas aqui. Consideravelmente mais difícil é a tentativa de dissociar o benefício em relação ao valor instrumental da vida vegetal que nos fornece, entre outras coisas, nutrição, oxigénio e fruição estética. Enquanto nos percebermos como estando obrigados pelos inestimáveis benefícios que retiramos das plantas, devemos-lhes respeito e, assim, colocamo-nos um nível abaixo delas. No entanto, esta justificação diverge da que David Schmidtz recentemente avançou ao afirmar que a "razão para termos em atenção outros seres vivos tem a ver com o auto-respeito"18. A fonte do problema não está reconhecidamente no argumento de Schmidtz, mas em Kant, onde a ultima ratio das valorações morais diferenciais aponta para os próprios atores humanos e para onde, como resultado, a presunção antropocêntrica é absurdamente instalada como a base do respeito. Todas as obrigações para com os seres vivos são filtradas pela obrigação humana em relação a si (o eu ideal, o superego, a subjetividade transcendental, a lei moral, e assim por diante) no que corresponde ao narcisismo moral que se apresenta sob a forma de especismo. A distância de respeito em relação às plantas e ao resto do mundo natural é internalizada, sublimada e idealizada, envolvida na subjetividade humana que se põe a si mesma acima de tudo o que avalia.

A segunda razão para colocar o ser humano abaixo das plantas deve ser procurada na filosofia grega antiga e, especialmente, na noção aristotélica de excelência, arete. Embora os seres vegetais e humanos compartilhem as capacidades da alma vegetal para a nutrição, crescimento e procriação, só as plantas podem ser ditas terem aperfeiçoado essas atividades. As suas realizações nestas áreas da vida não são apenas melhores do que o desempenho humano correspondente, mas também são "excelentes" na medida em que, na alimentação, crescimento e procriação, as plantas vivem de acordo com os seus fins inerentes (teloi), por mais abertos que eles sejam. Embora os humanos possam estar situados mais alto na grelha teleológica, as plantas são ontologicamente "superiores" na escala de valores reconstruídos a partir do ponto de vista da vida vegetal, a qual nos é largamente inacessível. Noutro lugar, referi-me a esta radicalização do pensamento de Nietzsche como

18 David Schmidtz, "Respect for Everything," Ethics, Policy, and Environment 14 (2011), 127-138. 
"perspectivismo generalizado", um corolário da transvaloração dos valores que leva em conta as diferenças entre os mundos e as formas de ter acesso ao mundo adequado às várias espécies ${ }^{19}$. Seguindo a lógica do perspectivismo generalizado, a distância ontológica constitutiva do respeito, assim como o sentido consentido de estar acima dos outros e da humildade de colocar-se abaixo deles, são questões de interpretação, decorrentes de posições e padrões de avaliação qualitativamente distintos. Em vez de um dado imutável, esta distância é o resultado de atos hermenêuticos concretos, à luz dos quais as plantas, entre outros seres vivos, são muito mais do que materiais para interpretação: são parceiros numa multiplicidade dispersa dos esforços hermenêuticos conjuntos que compõem a própria vida.

\section{II - A função reveladora do respeito}

A ideia de que as plantas são nossas benfeitoras merece uma atenção teórica mais detalhada porque coloca uma reviravolta inesperada na atitude instrumental em relação à vida vegetal, normalmente tratada como meio para os nossos próprios fins externos. Vale a pena, por exemplo, cultivar os diversos usos que os seres humanos dão às plantas com esta ideia, destacando a nossa obrigação assimétrica: como parceiras respeitadas no viver, elas ajudam-nos fornecendo alimento (ele próprio um princípio da alma vegetal), energia, abrigo, ar respirável e assim por diante. Como um amigo, na abordagem kantiana da filosofia moral, elas colocam-nos "um nível abaixo, ao estarmos obrigados sem sermos capazes de, em troca, impor uma obrigação" 20 . A réplica de que as plantações são cultivadas apenas para esses fins e são, portanto, dependentes dos cultivadores humanos é inadequada e prejudicial, porque, embora as plantas usem a água, solo e fertilizantes fornecidos pelos humanos, estes últimos utilizam as próprias plantas numa troca marcadamente desigual. Em todo o caso, a linguagem e atitude do uso e da instrumentalidade são escandalosos, no sentido em que Kant emprega a palavra "escândalo", como uma ofensa contra a respeitabilidade, pois violam

19 O perspectivismo nietzschiano, contestando a ideia de que não há senão uma verdade objetiva, aplica ambas às diferenças de perspectiva entre seres humanos e às diferenças entre entidades viventes humanas e não-humanas (daí o adjetivo "generalizado"). Enquanto, do ponto de vista do humano, o "homem" é, de facto, uma medida de todas as coisas, para a planta, o ser vegetativo é o padrão e ponto de referência último - "A planta é, portanto, um ser que mede" [Friedrich Nietzsche, Writings from the Early Notebooks, edited by Raymond Geuss and Alexander Nehamas (Cambridge: Cambridge University Press, 2009), 138].

20 Kant, The Metaphysics of Morals, 216. 
a nossa distância ontológica das plantas. $\mathrm{O}$ ato de comer é emblemático aqui, já que o comedor incorpora e assimila o que é comido e, ao fazê-lo, nega fisicamente a distância entre os dois, curiosamente alcançando o mesmo efeito que o amor, embora de uma forma que é, inegavelmente, mais destrutiva para as plantas. (No entanto, as práticas alimentares podem, também, tornar-se menos escandalosas, não tomando a forma de devorar indiscriminadamente plantas e partes de plantas, mas tomando a forma de uma comunhão de respeito com o que é comido que mantém um mínimo de dignidade, ou de distância ontológica. Tanto a qualidade quanto a quantidade de comida vão ser crucialmente afetadas por esta mudança de terreno, tornando eticamente permissível não comer nada senão as partes renováveis das plantas, em relação às quais temos uma enorme dívida e obrigação, concentrada no sentimento de respeito).

$\mathrm{O}$ reconhecimento respeitoso do endividamento humano e o sentimento de culpa em relação aos seres vegetais revelam a nossa dependência assimétrica, que é uma dimensão vital da ontologia relacional humano-planta. É frequentemente apontado que as plantas são independentes dos humanos aos quais preexistiam no tempo profundo da evolução ${ }^{21}$, mas o inverso não é o caso, porque a vida humana não teria sido possível sem plantas. Ser humano (e ser um animal) é ser dependente de seres vegetais quer onticamente como fornecedoras de alimentos, ar respirável, etc. - quer ontologicamente - como as indicadoras da vida na sua nudez, do viver como a capacidade para a nutrição, reprodução e crescimento. $\mathrm{O}$ respeito para com as plantas reconstitui os limites da autonomia humana e as placas de sinalização da nossa finitude.

Dentro do domínio estritamente antropocêntrico, a função reveladora do respeito recebe o tratamento mais sério na reformulação de Martin Heidegger da ética kantiana em Os problemas fundamentais da fenomenologia. "Neste sentimento de respeito", afirma Heidegger, "a autoconsciência moral, a personalitas moralis, a verdadeira personalidade do homem tem de se revelar" ${ }^{22}$. Mas deve revelar-se estritamente como uma auto-manifestação, isto é, na minha subjugação do meu "eu" a mim mesmo na capacidade do auto-legislador universal: "Eu sujeito-me, em respeito pela lei, ao meu próprio eu enquanto eu livre. Nesta sujeição de mim mesmo, eu sou manifesto

21 Carmen Velayos Castelo, "El Respeto por la Vida Vegetal. Vias de Justificacion." (ensaio inédito). Agradeço à Prof. Velayos Castelo pelas suas penetrantes questões acerca do tema da vida das plantas, no seguimento de uma palestra que dei no seu Departamento na Universidade de Salamanca, em Espanha, em Dezembro de 2010.

22 Martin Heidegger, The Basic Problems of Phenomenology, revised edition, translated by Albert Hofstadter (Bloomington \& Indianapolis: Indiana University Press, 1988), 133. 
a mim mesmo: eu sou como eu mesmo... Ao sujeitar-me a mim mesmo à lei, submeto-me a mim mesmo enquanto razão pura; mas isso quer dizer que nesta sujeição a mim mesmo eu levanto-me a mim mesmo para mim mesmo enquanto ser livre, autodeterminado" 23 . Eu estou, por outras palavras, à beira de ser, total e finalmente, eu mesmo. Se, por outro lado, eu devo respeito às plantas, tenho de consentir ser submetido a algo ou alguém além de mim mesmo, embora, para todos os intentos e propósitos, tal heteronomia, tal dependência do "outro" vegetal, ainda leve a forma de auto-sujeição, dado que as plantas não têm o poder, moral ou outro, para dar força a esta relação desequilibrada. A verdade revelada no sentimento do respeito vegetal pertence em igual medida ao ser dos seres humanos, ao nexo humano-planta, e à força bem como à respiração da autoconsciência moral.

Fenomenologicamente falando, o respeitar e o que é respeitado correspondem ao ato noético da consciência qua consciência de algo (o respeitar $d e . .$.$) e ao alvo noemático do respeito (o que é respeitado). Na versão$ kantiana-heideggeriana da ontologia moral, a noesis do respeitoso "ter-sentimentos-por" e o noema do respeito sentido giram numa órbita fechada da proximidade do ego para si mesmo, sendo por isso que o "respeito é o modo do estar-consigo-mesmo [Bei-sich-selbst-sein] do ego"24. Em contraste com esta camisa de forças solipsista de respeito no auto-respeito, a respeitabilidade das plantas revela um modo diferente do ser do ego, ou seja, o seu ser-com-o-outro. Aquele pelo qual temos um sentimento moral não coincide com nem cumpre teleologicamente o ter do sentimento: a correlação incestuosa de noesis e noema, unindo "eu" e "eu mesmo", rompe-se e admite algo ou alguém exterior ao eu. Para que o ego respeitoso se torne manifesto diante de si mesmo de uma maneira específica, para que ele seja onto-fenomenologicamente desobstruído para si mesmo, ele vai, doravante, ter de sair de si mesmo, esquecer que existe como seu próprio fim e, com o risco de nunca atingir o seu alvo noemático (o respeitado), bater-se pelo seu outro vegetal. Uma extensão da ética levinasiana da alteridade - ela mesma um corretivo a Kant, Husserl e Heidegger - às plantas está implícita neste priorização da heteronomia sobre a autonomia subjetiva, da "lei do outro" sobre a "lei da razão". Não será que o nosso respeito pelas plantas, como uma sinédoque do respeito pelo outro, se torna semelhante às plantas, na medida em que tende para o respeitado sem fim e sem fechamento, imitando o movimento aberto do crescimento vegetal?

Ao interromper a correlação noético-noemático, a função reveladora do respeito é moderada pela irredutibilidade do outro respeitado a objeto da consciência; "a pura 'desobstrução', onde ele [o outro] é proposto como

23 Heidegger, Basic Problems of Phenomenology, 135.

24 Heidegger, Basic Problems of Phenomenology, 135. 
tema, não o respeita suficientemente" 25 . O ser das plantas deve ser igualmente poupado a uma tematização profunda, se se trata de extrair, dentro da consciência que ativamente visa seu objeto, o tipo de humildade que caracteriza o respeito. A fim de frustrar a tematização e a objetivação das plantas, será necessário acentuar algo nelas que excede a sua identificação com meras coisas, ou seja, as características existenciais da sua ontologia: liberdade, temporalidade e intencionalidade não consciente ${ }^{26}$. Certamente, as conotações etimológicas do respeito como um ato de ter em conta e atenção, tanto no sentido fenomenológico como no sentido ético destes termos, pressagiam o movimento de desobstrução, ou, como Jacques Derrida coloca na sua crítica de Levinas, “... sem o fenómeno do outro enquanto outro nenhum respeito seria possível. O fenómeno do respeito supõe o respeito da fenomenalidade. E a ética a fenomenologia" 27 . Respeitar o outro, sugere Derrida, é considerar o outro como um fenómeno, não transformá-lo numa entidade numénica e misteriosa. Mas, não obstante esta réplica, a fenomenalidade do outro não pode ser diluída na presença da "auto-evidência". O outro não é algo ou alguém dado na plenitude da presença, entregue às operações de identificação de consciência. Qualquer afirmação em contrário desrespeita e perde de vista, no mesmo fôlego, o outro, pelo menos parcialmente retirado de vista.

Abordando respeitosamente o outro, estamos à beira de ver, desobstruir, indicar algo sobre a alteridade, mesmo que nos habituemos à ideia de que muita coisa dele vai permanecer imersa num tipo de obscuridade que nenhum conhecimento irá dissipar. É nesta chave que podemos tentar ler a história filosófica de atribuir obscuridade à vida vegetal - como São Tomás de Aquino escreve, na Summa Theologica, a "vida está escondida nas plantas [vita in plantis est occulta] $]^{28 "}$ - , a qual, ao tornar-se tematizada, se perde, precisamente, qua vida. Respeitar o ser das plantas não é enfaticamente equivalente a inspecioná-lo, a torná-lo totalmente visível, mesmo porque a nossa posição respeitosa de um grau abaixo das plantas (a posição literalmente associada à escuridão e ao fechamento da terra) não nos oferece nenhuma oportunidade de lançar um olhar panóptico ou um olhar horizontal para elas. Respeito é tanto mais uma fenomenalização desobstrutora quanto mais é

25 Levinas, Totality and Infinity, 71.

26 Dediquei um capítulo a cada um destes "existenciais vegetais" na segunda parte do meu livro Plant-Thinking: A Philosophy of Vegetal Life (New York: Columbia University Press, 2012).

27 Jacques Derrida, Writing and Difference, translated by Alan Bass (Chicago \& London: University of Chicago Press, 1980), 121

28 Thomas Aquinas, The Summa Theologica of Saint Thomas Aquinas, trad. pelos sacerdotes da Província Dominicana Inglesa e revista por Daniel J. Sullivan (Chicago: Encyclopedia Britannica, 1952), Q.LXIX, A2. 
uma retirada do papel de espectador e da relação especular com o outro. $\mathrm{Na}$ simples visibilidade da extensão vegetal fica sempre algo escondido, assim como as raízes da maioria das plantas vivas estão escondidas na escuridão do solo. A área cinzenta beirando a fenomenalidade é a província de respeito, acima de tudo, quando se trata da vida obscura das plantas.

Para sempre suspenso à beira do conhecimento, o respeito desvela, mais do que tudo, os limites da razão prática, para a qual ele nada é senão um suplemento, um "incentivo" (elater animi ${ }^{29}$, um sentimento paradoxal que não se encaixa de todo no conjunto de inclinações que definem a subjetividade empírica. Para Kant, o sentimento do respeito é dirigido necessariamente a uma pessoa, não a uma coisa, porque é um ato de loucura colocar-se voluntariamente abaixo de uma entidade não-racional, para mais uma entidade inanimada, perdendo assim a liberdade de cada $u^{30}$. Embora a oposição entre pessoas e coisas enquadre o conceito de respeito, os animais (e, efetivamente, as plantas) são relegados para o domínio das coisas, incapazes de provocar esse sentimento transcendental. Para com os animais, argumenta Kant, pode-se sentir amor, medo ou, na melhor das hipóteses, admiração "um afeto, uma surpresa, [que] pode ser direcionado também para as coisas, por exemplo, para altas montanhas, para a magnitude, o número e a distância de corpos celestiais, para a força e a rapidez do homem, de animais e assim por diante" 31 . Podemos analogamente admirar a tenacidade de plantas que se mantêm em climas duros e crescem através das rachaduras no concreto, ou tremer diante das suas dimensões e da sua diversidade, mas esses sentimentos estão muito aquém do respeito". Isto porque, enquanto nós apreciamos a nossa inferioridade em relação às qualidades particulares das plantas que achamos admiráveis, o objeto do respeito permanece ôntico, depende das características concretas dos seres e impede uma relação ontológica para com o ser destes entes. A admiração, sentida tanto por pessoas como por coisas, não coloca o eu admirador como um todo abaixo do que ele admira; a menos que tenham o hábito de adorar e venerar árvores sagradas, os seres humanos, impressionados com a grandiosidade de uma sequoia, não se curvam diante dela e não são, no seu próprio ser, revelados como estando abaixo da sequoia (mesmo quando estão fisicamente situados na sombra desta árvore imponente). Para resumir, enquanto a admiração, com suas conotações do milagroso e do maravilhoso que nos colocou à beira de um saber verdadeiramente filosófico, é afetada pelas qualidades ônticas dos seres admirados, o respeito é devido à constituição ontológica, ou ao ser, destes entes. O respeito pelas pessoas - ou, no caso, pela lei moral - manifesta a ontologia da persona-

29 Kant, Critique of Practical Reason, 62.

30 Kant, Critique of Practical Reason, 66.

31 Kant, Critique of Practical Reason, 66. 
lidade; o respeito pelas plantas, impossível dentro do esquema da filosofia kantiana, revela a ontologia do ser vegetal.

Seja como for, presta-se respeito ao que não pode ser visto, tocado ou acessado através de quaisquer outros sentidos: à personalidade e ao ser vegetal enquanto tal. As flexões semânticas do alemão Achtung e do Latim respectare (prestar atenção a, olhar para, respeitar, manter em alta conta) evocam coletivamente uma estranha orientação em relação ao que não pode ser olhado ou considerado. O respeito, considerado ontologicamente, paira à beira do ver sem tomar a representação do seu objeto. Enquanto inclinação, ele é um empenhar-se, um dirigir-se para alguma coisa que ele não alcançará nem captará e, portanto, ao mesmo tempo, um repulsa em relação ao seu objeto, ou, na apropriação por Heidegger do vernáculo filosófico do grego antigo, uma dioxis, "a maneira de procurar", e uma phuge, "submeter-se, fugir, retirar-se de" 32 . Para ser ontologicamente revelador, o respeito tem de seguir as regras do jogo do ser que é dado e retirado, que se entrega e retira de seu próprio ato de autodoação. $\mathrm{O}$ mesmo é verdadeiro para o respeito prestado ao ser das plantas que, em contraste com a mera admiração, reconhece a irredutibilidade do mundo vegetal em relação a algo que ocorre dentro do seu correlato humano. Como tal, o mundo das plantas, conceptualizado em termos existenciais como o ambiente a que acedem os entes vegetais a partir da sua própria perspectiva e que eles habitam à sua própria maneira, dá-se a si mesmo e retira-se da posse humana; respeitar este mundo é aceitar 1) a sua validade existencial para as plantas e comunidades de plantas que nele habitam e 2) a distância ontológica que separa este mundo do dos seres humanos. Uma vez aceites, estes dois postulados corroboram a impossibilidade de alguma vez tocar o mundo das plantas ou de tocá-lo de cima, impossibilidade que duplica enquanto condição de possibilidade do respeito.

Respeitar o ser das plantas significa respeitar a sua mundaneidade, o facto de que elas têm um mundo - em heideggerianês, poderíamos chamar a este facto de ter um mundo "facticidade vegetal" - e que este mundo é intocável $^{33}$, apesar de inúmeras tentativas de destruí-lo ao derrubar árvores, ao modificar geneticamente as culturas, ao levar espécies à beira da extinção e assim por diante. Entre o respeito kantiano pela lei universal e o respeito levinasiano pelos próprios entes singulares ("Mostrar respeito é curvar-se não diante de uma lei, mas diante de um ente que exige de mim um trabalho"34),

32 Heidegger, The Basic Problems of Phenomenology, 136.

33 Jacques Derrida chama respeito "a lei do tacto" ou o "toque sem tocar", que exige: "não toques nem lides com a coisa mesma, não toques onde houver que tocar" [On Touching-Jean-Luc Nancy, trad. Christine Irizarry (Stanford: Stanford University Press, 2005), 66]

34 Emmanuel Levinas, Collected Philosophical Papers, translated by Alphonso Lingis (Pittsburgh: Duquesne University Press, 1998), 43. 
o respeito pelo mundo singular-universal das plantas coloca-nos à beira do intocável. Quem quer que arranque uma flor, derrube uma árvore e, no auge do desrespeito, aspire a transformar as plantas que habitam o mundo em coisas que estão no e são do mundo humano falha em apreender o ser vegetal, confirmando que ele é intocável.

E, no entanto, numa estranha inversão de intencionalidade fenomenológica, o intocável toca-nos, por exemplo, quando certos traços do mundo vegetal se insinuam à existência humana. Se as capacidades de crescimento, de alimentação e de procriação são heranças que nos foram deixadas pelas plantas, e se reúnem sob o título de "alma vegetal", então este mundo estrangeiro, ou os modos de acesso ao mundo que de outro modo nos são inacessíveis, formam, sem o nosso conhecimento, uma parte substancial da nossa existência. Antes de mostrar respeito ao outro vegetal, seria aconselhável aprender a respeitar suas reverberações dentro de nós, em vez de descartá-las como os aspectos menos respeitáveis, automáticos, involuntários da condição humana. Se, além disso, a função reveladora do respeito for levada a sério, então, numa distância não atravessável em relação a nós mesmos, seremos revelados a nós mesmo como um outro em relação a quem ou a que somos - como uma instância de "coisas que crescem", phutoi. Uma mera premonição desta comunhão é suficiente para incutir humildade e diminuir a presunção associada com o antropocentrismo, fortalecendo assim o sentimento de respeito. Mais verdadeira do que "a verdadeira personalidade do homem" que the permite tornar-se ele mesmo ao tomar posse livremente de si mesmo, a auto-revelação do humano como uma espécie de planta estabelece os limites da auto-apropriação, do movimento por meio do qual "eu ergo-me a mim mesmo para mim mesmo como o ser livre que se determina a si mesmo". (É esta barreira à apropriação de "o que é" que, de acordo com Levinas, define o respeito. ${ }^{35}$ ) Correlativamente, ao respeitar e deixar florescer a planta em mim, eu abaixo-me a mim mesmo para mim mesmo sem tematizar completamente as capacidades involuntárias e largamente incontroladas da alma vegetal que opera dentro de mim. A distância entre o eu consciente e o meu outro lado não consciente é intransponível: o respeito para com o outro vegetal em mim põe-me à beira da desobstrução para mim mesmo e, ao mesmo tempo, instiga uma atitude respeitosa em relação a todas as outras "coisas que crescem".

\section{Qual é o sentido do respeito pela vida vegetal?}

O que significa respeitar o próprio ser das plantas, entendido em termos heideggerianos como o ser do seu mundo? Ou, posto de outra maneira, quais

35 Levinas, Totality and Infinity, 302. 
são as características ontológicas das plantas que as separam de nós e, no mesmo golpe, as tornam nas destinatárias de uma atitude respeitosa? Em resposta a estas perguntas, as páginas restantes contêm uma interpretação preliminar da noção de mundanidade vegetal com todos os apetrechos ontológicos geralmente associados à ideia fenomenológica de mundo. É, em última análise, a mundanidade das plantas - a sua existência no sentido existencial (não essencial) desta palavra - que provoca o nosso respeito por seres vegetais, um sentimento análogo ao mas também qualitativamente diferente do respeito devido às pessoas humanas.

O mundo da vida das plantas é um reino de espacialidade e temporalidade existenciais, adaptado ao seu modo de $\operatorname{ser}^{36}$. Em vez de coisas passivamente depositadas no mundo, as plantas relacionam-se com o seu ambiente e com o tempo-espaço do crescimento. A imersão e, de facto, o enraizamento de uma planta no lugar do seu crescimento tem sido frequentemente tomado como um sinal de sua inferioridade em relação ao animal, definido pela sua capacidade de se opor ao seu lugar, ou para se mover alterando a sua posição ${ }^{37}$. A quase fusão dos seres vegetais com seus lugares não deve, no entanto, diluir o sentimento de respeito; pelo contrário, sob este ponto de vista, uma consideração ética das plantas é equivalente a respeitar os locais do seu crescimento. Consistente com várias correntes da ética orientadas para o contexto, tais como a ética do lugar de Edward Casey ${ }^{38}$, o respeito pelo enraizamento é apropriado para a espacialidade existencial dos seres vegetais que formam o seu meio de uma forma totalmente afirmativa, sem a mediação de decisões conscientes de ficar ou partir, de manter-se ou de seguir viagem, de afirmar ou negar um lugar. De modo a completar esta imagem da espacialidade vegetal adicionemos à íntima relação das plantas com os lugares que habitam a complexidade de sua expressão (muda) ou da sua auto-elaboração através de uma proliferação de formas, extensões e posições. A consideração ética pela sua expressão espacial quererá dizer, então, respeitar 1) a mudez das plantas, rejeitando a tentação de falar por elas, em seu lugar, e 2) o facto de que cada planta é uma corporização concreta do sentido vegetal que pe-

36 Para mais, no que respeita aos traços ontológicos da vida vegetal, consulte-se o meu livro Plant-Thinking: A Philosophy of Vegetal Life, passim.

37 Para um caso paradigmático de tal interpretação, veja-se G.W.F. Hegel, Philosophy of Nature: Encyclopedia of the Philosophical Sciences, Part II, trad. A.V. Miller (Oxford: Oxford University Press, 2004), 303-351.

38 "Emerge um novo sentido de responsabilidade no qual os seres humanos têm um compromisso duradouro em relação a respeitar a Terra - isto é, os seus locais telúricos e aquosos - assim como os membros das outras espécies. Mesmo a nossa responsabilidade em relação a humanos é, em última análise, responsabilidade em relação a pessoas nos lugares..." [Edward S. Casey, Getting Back into Place: Toward a Renewed Understanding of the Place-World (Bloomington \& Indianapolis: Indiana University Press, 1993), 264]. 
rece com a própria planta. A perda desta árvore de carvalho, desta roseira, deste dente de leão, desta hera explicita a perda dos lugares e dos sentidos coextensivos com estes seres que são infinitamente mais do que espécimes ou representantes de um género facilmente substituíveis e intercambiáveis.

Embora a temporalidade das plantas esteja bifurcada no tempo em aberto do crescimento e no tempo cíclico de reprodução, ele está invariavelmente sintonizado com algo fora das próprias plantas (mudanças sazonais, a posição do sol, e assim por diante). A regulação humana do crescimento vegetal por meio de produtos químicos, hormonas, manipulação genética ou gases, como o 1-metilciclopropeno, que tanto aceleram quanto retardam a maturação da fruta, é, na verdade, uma tentativa de usurpar o lugar do "outro inorgânico" das plantas, seja ele o Sol ou as condições ambientais em geral, reduzindo assim a distância ontológica necessária para uma atitude de respeito para com elas. Mais alarmante ainda é a bioengenharia e o patenteamento de sementes não-renováveis, pois não só essas atividades se esforçam por apropriar e, ao apropriar, por violar o ser das plantas, mas também aproveitam as suas potencialidades num tipo de violência ontológica. Esta interferência com o tempo das plantas é um escândalo, uma ofensa contra a respeitabilidade, e uma difamação do seu ser temporal, determinado pelas capacidades ativas (dunamei) da alma vegetal. Roubadas do seu próprio futuro e colocadas ao serviço da temporalidade agro-capitalista, sementes bioengenharizadas não reproduzem nada senão o próprio capital, com lucros suplantando o tempo das plantas.

Se se analisar a espacialidade ou a temporalidade das plantas, muita coisa muda no sentido da liberdade dentro do contexto da sua vida. Aqueles que interpretam a sua liberdade em termos de autonomia, supondo que a ligação à exterioridade é incompatível com esse ideal, chegam perto de impor como autonomia ao mundo das plantas uma compreensão de liberdade antropocêntrica, masculina, ocidental e metafísica altamente circunscrita ${ }^{39}$. A dependência radical das plantas em relação aos locais em que crescem, na mudança de estações, e o resto do frágil contexto da sua existência indicam que a sua liberdade é heterónoma, isto é, que ela cresce a partir da sua dependência radical em relação ao outro. O que será preciso para respeitar a liber-

39 Apesar de simpatizar com o repensar da ética das plantas de Matthew Hall, não concordo que as reivindicações que defendem a autonomia das plantas sejam necessárias para garantir o seu estatuto ético. Como referi na introdução a este artigo, não há simplesmente nenhuma razão para se apegar ao valor da autonomia no que respeita à vida das plantas, depois de um completo questionamento deste valor no discurso feminista, pós-estruturalista e outros do século XX. Para o argumento de Hall, refira-se Matthew Hall, "Plant Autonomy and Human-Plant Ethics," Environmental Ethics, Vol. 31, Summer 2009, 169-181 bem como o mais recente Plants as Persons (2011). 
dade vegetal reconfigurada como heteronomia? Vendo que as plantas, de que dependemos de uma miríade de formas e de que somos devedores, dependem, por sua vez, do seu outro inorgânico, o respeito para com elas é tanto mais ligado a uma consideração ética pelos locais onde elas crescem e pelo ambiente como um todo. Por mais nobre que seja a intenção por detrás dele, o princípio de não-interferência com o ser vegetal torna-se inútil enquanto este ser estiver sempre "temperado com", constituído em relação ao outro do qual não está separado. É concebível que o valor de preservar a selva, onde as plantas dependem exclusivamente do mundo inorgânico, viesse à tona com referência à heteronomia vegetal, como acontece no "respeito pela natureza" de Taylor ${ }^{40}$. Mas é também concebível que, por vezes, os seres humanos entrem respeitosamente, sem ocupar permanentemente, o lugar do outro das plantas, desde que não reduzam, por isso, a distância ontológica que os separa das plantas e que alimentem a riqueza de potencialidades pertencentes à vida vegetal. As exigências de atender as potencialidades da ontologia das plantas e de as guardar contra ficarem esgotadas ou empobrecidas explica a necessidade de levantar a questão do respeito de novo em cada situação quando e em cada lugar onde nos envolvemos ou deixamos de envolver com plantas. É por isso que as tentativas de formular um princípio universal de respeito pela vida das plantas, um princípio divorciado dos contextos singulares do florescimento desta vida, estão equivocados.

Finalmente, a existência vegetal apresenta a intencionalidade não consciente e bifurcada do crescimento, tendendo espacialmente para o céu e para a terra, para a luz do Sol e para nutrientes minerais. Na ausência de fechamento, de completude e de interioridade subjetiva isolada do mundo exterior, esta existência é totalmente virada para fora e essencialmente superficial. Aqueles que estão prontos para prestar respeito à intencionalidade não consciente da vida vegetal terão de se abster de compará-la com a vontade do animal e com a orientação consciente do humano, do mesmo modo que terão de evitar transformá-la numa figura de deficiência, numa modalidade negativa da consciência. $\mathrm{O}$ respeito para com as plantas exige que apreciemos a plenitude e a positividade do que, do nosso ponto de vista, se anuncia invariavelmente no negativo: não consciência, insensibilidade, indiferença, falta de resposta... Pura positividade que preexiste à distinção entre o positivo e o negativo, a exuberância vegetal escapa a ser capturada e domada pela conceptualidade filosófica; a proliferação excessiva de plantas - por exemplo, na densidade de uma selva - reflete onticamente a sua intencionalidade não consciente e excede os quadros da filosofia, incapaz de abarcar esta produção e reprodução de vida imoderada e imensurável. Prestar respeito à

40 Taylor privilegia a categoria da "vida selvagem" ao discutir as regras da não-interferência e não-maleficência em Respect for Nature, 192-198. 
positividade absoluta da existência vegetal significa libertar um espaço não-hierarquicamente situado entre a profundidade subjetiva dos humanos, que é, talvez, apenas um ilusão transcendental, e a superfície das coisas inanimadas.

Tomada como um todo, a espacialidade e a temporalidade existenciais do crescimento, a liberdade heterónoma e a intencionalidade não consciente da vida vegetal compreendem o ser, ou a mundaneidade, do mundo das plantas. Enquanto estas variáveis onto-existenciais são também tidas em conta na existência humana e na incorporação enquanto tal, a distância entre os dois mundos é inegável. Ao respeitar as plantas, respeito o seu mundo enquanto mundo, dando atenção a esta distância, a esta separação que, ao mesmo tempo, impede a desvinculação absoluta e a absolvição do seu mundo em relação ao meu próprio mundo. À beira do respeito, estou sempre à beira de um outro mundo que é o mundo do outro, mesmo que seja tão discreto quanto uma planta. 